University of Arkansas, Fayetteville

ScholarWorks@UARK

10-1-2015

\title{
Discipline Disproportionalities in Schools: The Relationship between Student Characteristics and School Disciplinary Outcomes
}

\author{
Kaitlin Anderson \\ Michigan State University, ande2018@msu.edu \\ Gary W. Ritter \\ University of Arkansas, Fayetteville
}

Follow this and additional works at: https://scholarworks.uark.edu/edrepub

Part of the Educational Assessment, Evaluation, and Research Commons, Educational Leadership Commons, and the Other Educational Administration and Supervision Commons

\section{Citation}

Anderson, K., \& Ritter, G. W. (2015). Discipline Disproportionalities in Schools: The Relationship between Student Characteristics and School Disciplinary Outcomes. Education Reform Faculty and Graduate Students Publications. Retrieved from https://scholarworks.uark.edu/edrepub/42

This Article is brought to you for free and open access by the Education Reform at ScholarWorks@UARK. It has been accepted for inclusion in Education Reform Faculty and Graduate Students Publications by an authorized administrator of ScholarWorks@UARK. For more information, please contact scholar@uark.edu. 


\title{
Q UNIVERSITY OF | The Department of ARKANSAS Education Reform
}

\section{WORKING PAPER SERIES}

Discipline Disproportionalities in Schools: The Relationship Between Student Characteristics and School Disciplinary Outcomes

\author{
Kaitlin P. Anderson \\ Dr. Gary W. Ritter
}

October 2015

EDRE Working Paper 2015-08

The University of Arkansas, Department of Education Reform (EDRE) working paper series is intended to widely disseminate and make easily accessible the results of EDRE faculty and students' latest findings. The Working Papers in this series have not undergone peer review or been edited by the University of Arkansas. The working papers are widely available, to encourage discussion and input from the research community before publication in a formal, peer reviewed journal. Unless otherwise indicated, working papers can be cited without permission of the author so long as the source is clearly referred to as an EDRE working paper. 


\title{
Discipline Disproportionalities in Schools:
}

\section{The Relationship Between Student Characteristics and School Disciplinary Outcomes}

Kaitlin P. Anderson (kaitlina@uark.edu), The University of Arkansas, Fayetteville, AR

Gary W. Ritter, PhD (garyr@uark.edu), The University of Arkansas, Fayetteville, AR

\begin{abstract}
According to a 2014 report from the US Department of Education's Office for Civil Rights, black students represent only $15 \%$ of students across the nation, but $35 \%$ of students suspended once are black, $44 \%$ of students suspended more than once are black, and $36 \%$ of expelled students are black. These disparate disciplinary aggregate outcomes, while troubling, do not provide as much information as policymakers need. In this study, we exploit three years of student-level discipline data from Arkansas to assess the extent to which black students or other minority students were more likely to receive certain types of punishments, even for the same infraction. In previous studies utilizing the same dataset, we find that, consistent with the recent reports on this topic, black students were punished more frequently; furthermore, we find that black students received slightly longer punishments than their white peers in the same school. The current study utilizes multinomial logit to assess the extent to which student demographics predict consequence type, even after controlling for infraction-level information and district characteristics. Black students, males, and low-income students (eligible for free- and reduced- lunch) were more likely to receive certain types of exclusionary consequences such as out-of-school suspension, expulsion, and referrals to Alternative Learning Environments relative to in-school-suspension.
\end{abstract}

Key words: school discipline, schooling outcomes, racial inequality, exclusionary discipline

**DRAFT - Please do not cite or distribute without author permission** 


\section{INTRODUCTION}

Schools must do what is reasonable and necessary to ensure the safety of students, teachers, and staff, and in extreme cases, schools may need to remove a student from the campus. Some claim, however, that there is an over reliance on exclusionary discipline practices such as expulsions and suspensions that remove students from the learning environment, and ultimately lead to a host of negative effects. Decades of research have consistently found that African American youth are overrepresented in exclusionary disciplinary practices such as suspension and expulsion (Children's Defense Fund, 1975; Skiba et al., 2002).

In an effort to address these disparities in disciplinary outcomes, the United States Department of Justice (USDOJ) and the United States Department of Education (USDOE) issued a "Dear Colleague Letter" in January of 2014. The letter goes to great lengths to explain two ways in which disciplinary policies can violate students' civil rights: different treatment and disparate impact. In the years following Brown v. Board, schools have had fewer and fewer instances of civil rights violations through different treatment. For the most part, policies and procedures appear to be fair in both their writing and delivery. However, there is evidence showing that certain races and students with disabilities, have been subject to the disparate impact of disciplinary policies, which is still evidence of a civil rights violation, according to the USDOJ and USDOE.

The overall use of exclusionary discipline practices such as out-of-school suspension (OSS) has increased for almost all racial groups over the last three decades (OCR). Recently, the OCR data demonstrated racial disparities in discipline policies. For example, black students in 2011-12 made up only $15 \%$ of the students represented in the Civil Rights Data Collection (CRDC), but 35\% of students suspended once, $44 \%$ of those suspended more than once, and $36 \%$ of students expelled. 


\section{LITERATURE REVIEW}

Looking at suspension rates for first time offenders in North Carolina, Losen (2011) finds black students are more likely than white students to be suspended for relatively minor offenses. For example, black students are more than twice as likely to be suspended for their first offense of insubordination related to cell phone use. Similarly, black students in North Carolina are being removed from school at higher rates than their white peers for dress code violations, disruptive behavior, and public displays of affection.

Using a national sample of disciplinary data from 436 schools, Skiba et al. (2011) find similar results. Black and Latino students were more likely than their white peers to be suspended or expelled from school for insubordination. Skiba et al. (2011) use logistic regression to find that black students were 2.19 times more likely than their white peers to be sent to the office for insubordination in elementary school and 3.78 times more likely in middle school. This study does not control for schoollevel characteristics, a contribution that the current study makes.

In addition, Skiba et al. (2011) use multinomial logit regression to estimate differences in the probability of certain types of consequences (detention, moderate consequence, ISS, OSS, and other/unknown) for certain categories of infractions (minor misbehaviors, disruption, noncompliance, moderate infractions, major violations, use/possession, and other/unknown). They find that black elementary students were more likely than white elementary students to receive OSS for minor misbehaviors and that Latino students at the elementary level were more likely to be suspended or expelled than their white peers for all infractions except disruption.

Multinomial logit regression is also used by Sullivan, Klingbeil, and Van Norman (2013), who find that gender, race, disability, and socioeconomic status were all significant predictors of students' suspension risk (none, one, or two suspensions). However, school demographics, performance, and teacher characteristics were not. 
As a way to "parse out" which factors (student level demographic, student level behavioral, or school level) predict the risk of suspension or expulsion, Skiba et al. (2014) use multinomial logistic regression within a hierarchical modeling approach. The multilevel approach accounts for the nesting of students within classrooms and classrooms within schools. Using this approach, they find that the type of infraction, student characteristics (race, gender, and socioeconomic status), and school characteristics (black enrollment rate and principal perspectives on school discipline) were significant predictors of the likelihood of suspension. At least for racial disparities in suspension and expulsion rates, they find that school-level characteristics are more important predictors than student-level characteristics.

Overall, recent empirical research finds racial disparities in disciplinary outcomes across the United States. In Arkansas, the story of racial gaps is even more troubling than the national average. Arkansas Advocates For Children and Families (2013) report that Arkansas schools too often rely on disciplinary measures that remove students from the classroom, limiting their ability to learn. In 200910, Arkansas ranked 13th in the disparity between the suspension risk for black and white students as measured by a black-white percentage gap of 13.2 (Losen \& Gillespie, 2012). Losen and Gillespie calculate this gap as the difference in the percent of black students receiving one or more suspensions in $2009-10(18.5 \%)$ and the percent of white students receiving one or more suspensions in the same year $(5.3 \%){ }^{1}$

In previous work utilizing the same data as this current study, we find that black students in Arkansas received more severe punishments (in terms of numbers of days of consequences), even after controlling for a variety of infraction level factors and the school they attended (Anderson et al., forthcoming). The results indicate that there were large differences in the length of punishment (half a

\footnotetext{
${ }^{1}$ According to our data, the 2010-11, 2011-12, and 2012-13 black-white gaps using the Losen and Gillespie method are $10.7 \%, 11.0 \%$, and $11.5 \%$, respectively.
} 
day per infraction) between African-American students and white students when the only controls were race, grade, special education status, and whether the type of consequence was expulsion. However, when controls for the type of infraction committed and for the number of previous infractions that year are included, the difference between the average punishment for African American students and white students decreases to about one third of a day per infraction. Furthermore, when school-fixed-effects are included, the difference, though still statistically significant, is reduced to less than one tenth of a day. The results indicate, therefore, that most of the variation in the disproportionalities for African-American students is due to differences between schools, rather than to disparities within the same school.

\section{Research Question}

The current study will attempt to answer the following research questions:

1. Holding constant the factors that could justifiably predict a disciplinary consequence (type of infraction, order of infraction (i.e. number of repeat offenses), and elementary v. secondary school) does a student's race predict the type of consequence received?

2. After additionally controlling for district level characteristics (size, demographics, and region), does a student's race still predict the type of consequence received?

3. Among the socio-economic and demographic indicators that should not be related to disciplinary outcomes, if discipline is administered fairly and consistently, which is the largest driver of the disparities in disciplinary outcomes?

\section{DATA AND SAMPLE}

\section{Descriptions of Data and Sample}

The study uses three years of de-identified disciplinary and demographic data from all K-12 schools in Arkansas provided by the Arkansas Department of Education (2010-11 through 2012-13). 
These data represent virtually all infractions entered into Arkansas school discipline databases and their corresponding consequences. The composition of the discipline data by gender, race, and other attributes looks somewhat different than the Arkansas student population overall, as indicated in Appendix A. These discipline data, which are composed of infraction level information and therefore include some students more than once, are made up of infractions and consequences only for students who are actually cited for infractions. As a result, the observations in these data are related to students who are disproportionately male, black, FRL-eligible, in special education, and in higher grades (6-12) than the overall population.

The discipline data received from the state of Arkansas include nineteen infraction codes and thirteen consequence codes. To simplify the analysis and create more consistency, we collapsed infractions involving either handguns, rifles, or shotguns into a single category. This resulted in only seventeen distinct categories. Furthermore, thirteen consequence categories were combined into seven distinct disciplinary consequence categories. ${ }^{2}$

Additional student level information includes demographic information such as gender, race, grade level, special education status, limited English proficiency-status, and FRL eligibility.

\section{Sample Descriptive Statistics}

After removing duplicates entries (those that had the exact same student, discipline date, infraction code, consequence code, as well as the same student-level demographic variables) there were 651,804 total observations over the three year period. The breakdown by infraction and consequence can be seen in Tables 1 and 2 below.

\footnotetext{
${ }^{2}$ The original 13 consequence categories were In-School Suspension, Out-of-School Suspension (when the incident did not result in physical injury), Out-of-School Suspension (when the incident did result in physical injury), Expelled, Expelled for Weapons (as defined by Federal, State, and Student Discipline Policy), Expelled for Drugs (does not include alcohol or tobacco), Expelled for dangerousness (the incident did not result in physical injury), Expelled for dangerousness (the incident resulted in physical injury), Alternative Learning Environment (full year), Alternative Learning Environment (less than one year), Corporal Punishment, No Action, and Other.
} 
Table 1: Arkansas K-12 Discipline Data by Infraction (2010-11 to 2012-13)

\begin{tabular}{lrrr}
\hline & \multicolumn{3}{c}{ Total Discipline Data } \\
\hline & \multicolumn{1}{c}{$\begin{array}{c}\text { Annual } \\
\text { Number of } \\
\text { Infractions } \\
\text { (3-Years) }\end{array}$} & $\begin{array}{c}\text { \%o of } \\
\text { Sample } \\
\text { (3-Years) }\end{array}$ & $\begin{array}{c}\text { per 100 } \\
\text { Students }\end{array}$ \\
\hline Disorderly Conduct & 196,567 & $30.2 \%$ & 13.9 \\
Insubordination & 170,958 & $26.2 \%$ & 12.1 \\
Other (Non-specified) & 133,952 & $20.6 \%$ & 9.5 \\
Fighting & 50,422 & $7.7 \%$ & 3.6 \\
Truancy & 49,096 & $7.5 \%$ & 3.5 \\
Bullying & 18,118 & $2.8 \%$ & 1.3 \\
Tobacco & 9,289 & $1.4 \%$ & 0.7 \\
Student Assault & 7,330 & $1.1 \%$ & 0.5 \\
Drugs & 6,500 & $1.0 \%$ & 0.5 \\
Miscellaneous* & 9,572 & $1.5 \%$ & 0.7 \\
\hline Total & $\mathbf{6 5 1 , 8 0 4}$ & $\mathbf{1 0 0 . 0 \%}$ & $\mathbf{4 6 . 1}$ \\
\hline
\end{tabular}

*Includes: Vandalism, Knife, Staff Assault, Alcohol, Gangs, Guns, Club, Explosives

Table 2: Arkansas K-12 Discipline Data by Consequence (2010-11 to 2012-13)

\begin{tabular}{lrrr}
\hline & \multicolumn{3}{c}{ Total Discipline Data } \\
& $\begin{array}{c}\text { Annual } \\
\text { Number of } \\
\text { Infractions } \\
\text { (3-Years) }\end{array}$ & $\begin{array}{c}\text { \% of } \\
\text { Sample } \\
\text { (3-Years) }\end{array}$ & $\begin{array}{c}\text { Incidences } \\
\text { per 100 } \\
\text { Students }\end{array}$ \\
\hline ISS & 261,759 & $40.2 \%$ & 18.5 \\
OSS & 175,012 & $26.9 \%$ & 12.4 \\
Other (Non-Specified) & 111,785 & $17.2 \%$ & 7.9 \\
Corporal Punishment & 93,222 & $14.3 \%$ & 6.6 \\
No Action & 5,159 & $0.8 \%$ & 0.4 \\
ALE & 3,021 & $0.5 \%$ & 0.2 \\
Expulsion & 1,846 & $0.3 \%$ & 0.1 \\
\hline Total & $\mathbf{6 5 1 , 8 0 4}$ & $\mathbf{1 0 0 . 0 \%}$ & $\mathbf{4 6 . 1}$ \\
\hline
\end{tabular}

\section{Limitations of the Data}

The data utilized in this analysis are district/school administrative data rolled up to the state level. As a result of differences in infraction and consequence categories at the state and local level, a large number of infractions and consequences were categorized as "other" when collected by the state. 
Over $95 \%$ of the "Other (Non-Specified)" consequences can be attributed to four types of infractions: disorderly conduct, insubordination, other (non-specified) infractions, and truancy.

\section{An Additional, More Nuanced, Limitation of the Data}

We are confident that the data presented here and in the forthcoming analysis contribute to the current literature, much of which is not able to control for as many infraction-specific details as the current dataset. However, we must acknowledge that there are still key parts of the picture that we cannot observe in this dataset (or in any dataset).

To illustrate the sequence of events connected to school disciplinary infractions, we will walk through a simple example.

1) A student curses out a teacher in the hallway in front of a school administrator.

2) The administrator chooses to write the student up for insubordination.

3) The administrator then issues a 2-day in-school suspension (ISS) to the student.

Looking backwards at these three distinct events, it seems clear that our analysis (and many others before ours) benefits from a direct observation of event 3 . That is, we have a clear count of the disciplinary consequence. Our analysis is distinguished from many others in that we have data that also include observations of event 2 in the simple illustration above. Thus, we can assess the extent to which students are receiving similar consequences for similar offenses. Unfortunately, however, our dataset provides no information on the actual actions of the students and or administrators involved; we are unable to observe event 1 from our fictitious example above.

Our inability to observe the actual infraction (event 1) has numerous implications. For example, we don't observe misbehaviors that were never written up, and we do not know the severity of the infraction committed. Certain infraction categories are more subjective than others. For example, the three biggest categories of infractions, disorderly conduct (30.2\%), insubordination (26.2\%), and other non-specified (20.6\%) can include a wide range of behaviors and are subject to teacher or 
administrator discretion. Therefore, while we are able to consider potential disparities even after controlling for infraction, we do not claim to paint a full picture of all discipline related disparities. In addition to whatever disparities we may observe, it is also possible that school administrators actually write up certain types of students while overlooking similar misbehaviors from other students. Finally, it is also possible that the differences in consequences are related to differences in the severity of an action within a specific infraction code, which is unobserved. For example, we have no knowledge on how severe any given act of "disorderly conduct" is.

Nevertheless, these limitations exist in all large scale studies on school discipline, because there is no practical way to collect this missing information. The inability to observe the actual behavior, whether or not it leads to a referral, implies simply that we must use caution in interpretation. We now turn to the analytic methods we use to explore the relationship between student demographic factors and disciplinary outcomes.

\section{METHODS}

Multinomial logit will be used to measure disproportionality by race in the multiple categories of discipline outcomes, holding infraction type constant and controlling for a variety of additional factors in different models. Heteroskedastic-robust standard errors clustered at the student level are used. The relative risk ratio of receiving a certain consequence relative to a base consequence, will be estimated, where a relative risk ratios greater than 1.0 indicate overrepresentation of a subgroup and values less than 1.0 indicate underrepresentation.

Model 1, which is aligned with the first research question focused on the relationship between race and disciplinary outcomes, includes the following covariates:

- A vector of binary student race indicators (with white as the baseline) 
- A binary indicator of secondary grades (ninth through twelfth; the baseline is pre-Kindergarten through eighth grade

- A vector of binary indicators for infraction type (with disorderly conduct as the baseline)

- A vector of binary indicators for first, second, third, fourth, fifth, sixth, seven or more infraction (student by school by year) plus last infraction; These are created as the order for the same student, within the same school and the same school year (first infraction and not last infraction are the baselines)

Model 2, which is aligned with the second research question that adds control variables for district characteristics, includes the same covariates as Model 1 with the addition of:

- District $\log ($ enrollment $)$

- District percent minority (non-white)

- District percent FRL-eligible

- District percent special education

- A vector of binary indicators for region (with the Northwest region as the baseline)

Model 3, which is aligned with the third research question adding in additional student level demographic controls, includes the same covariates as Model 2 with the addition of:

- Student demographics (gender, FRL status, special education status, and limited English proficiency)

\section{RESULTS}

Research Question 1: Holding constant the factors that could justifiably predict a disciplinary consequence (type of infraction, order of infraction (i.e. number of repeat offenses), and elementary $v$. secondary school) does a student's race predict the type of consequence received? 
The results of Model 1 are given in Table 3. Model 1 includes only race (the variable of interest), plus the factors that should theoretically predict the disciplinary consequence if discipline policies and practices were fair and consistent across the state. These covariates include the infraction committed, indicators for repeat offenses, and whether the student was attending an elementary (K-8) or secondary (9-12) school. The relative risk ratio of receiving a certain consequence is reported, where a relative risk ratio greater than 1.0 indicates that a subgroup is overrepresented in a certain consequence type, relative to the reference consequence (In-School Suspension) and a relative risk ratio less than 1.0 indicates that a subgroup is underrepresented in a certain consequence type, relative to the reference consequence. Thus, these ratios represent the degree of disproportionality in certain consequences, holding all other factors constant.

The first model predicts the relative odds of receiving different types of consequences, relative to ISS, for different races. The results for Model 1 in Table 3 indicate that all else equal, being African American increases the relative odds of receiving OSS, expulsion, or referral to an ALE, and decreases the relative odds of receiving corporal punishment, no action, or "other" action relative to white students. In addition, being Hispanic increases the relative odds of receiving an "other (non-specified)" action and decreases the relative odds of receiving OSS, corporal punishment, or no action, relative to white students. The relative odds for other, less populous groups of students by race are also included. The most striking result from Model 1 is that being African American increases the relative odds of receiving a referral to an Alternative Learning Environment (ALE) by over six times. This means that African American students are more than six times as likely as their white peers in the state to be placed in an ALE for the same type of infraction. Another striking, though puzzling result, is that for all non-white races except for black students, the likelihood of receiving an "other" action are higher than the likelihood of receiving ISS. This result is hard to interpret in this first model without knowing 
Table 3: Multinomial Regression of Type of Consequence, Arkansas K-12 (2010-11 to 2012-13); Relative-Risk Ratios

\begin{tabular}{|c|c|c|c|c|c|c|c|c|c|c|c|c|}
\hline \multirow[b]{2}{*}{ Group } & \multicolumn{6}{|c|}{ MODEL 1} & \multicolumn{6}{|c|}{ MODEL 2} \\
\hline & $\begin{array}{l}\text { Out-of-School } \\
\text { Suspension }\end{array}$ & Expulsion & $\begin{array}{c}\text { Corporal } \\
\text { Punishment }\end{array}$ & ALE & No Action & Other Action & $\begin{array}{c}\text { Out-of-School } \\
\text { Suspension }\end{array}$ & Expulsion & $\begin{array}{c}\text { Corporal } \\
\text { Punishment }\end{array}$ & \multirow[t]{2}{*}{ ALE } & No Action & Other Action \\
\hline Race/Ethnicity & & & & & & & & & & & & \\
\hline Black & $2.089 * * *$ & $1.983 * * *$ & $0.648 * * *$ & $6.577 * * *$ & $0.769 * * *$ & $0.626 * * *$ & $1.090 * * *$ & $1.445 * * *$ & 1.043 & $1.358 * * *$ & 1.026 & $0.785 * * *$ \\
\hline Hispanic & $0.854 * * *$ & 0.881 & $0.306^{* * *}$ & 1.211 & $0.315 * * *$ & $1.844 * * *$ & $0.752 * * *$ & 0.994 & $0.660 * * *$ & $0.577 * * *$ & $0.433 * * *$ & $1.192 * * *$ \\
\hline Asian & 0.996 & $0.313 * *$ & $0.299 * * *$ & 0.406 & $0.261 * * *$ & $2.002 * * *$ & 0.900 & $0.388 *$ & $0.688 * *$ & $0.281 * *$ & $0.320 * * *$ & $1.161 * *$ \\
\hline Native American & $0.830 * * *$ & 0.699 & $0.496 * * *$ & $0.111 * *$ & $0.480 * * *$ & $1.772 * * *$ & $0.869 * *$ & 0.839 & $0.777 *$ & $0.0997 * *$ & $0.552 * *$ & $1.175^{* *}$ \\
\hline Two or More Races & 0.961 & 0.694 & $0.587 * * *$ & 1.038 & 0.928 & $1.584 * * *$ & $0.850 * * *$ & 0.728 & 1.012 & 0.761 & 1.103 & $1.098 * *$ \\
\hline Grade 9-12 & $1.096 * * *$ & $1.896 * * *$ & $0.352 * * *$ & $1.506 * * *$ & $0.527 * * *$ & $0.867 * * *$ & $1.117 * * *$ & $1.966 * * *$ & $0.356 * * *$ & $1.432 * * *$ & $0.534 * * *$ & $0.792 * * *$ \\
\hline \multicolumn{13}{|l|}{ Infraction Type } \\
\hline Insubordination & $0.707 * * *$ & $0.543 * * *$ & $0.833 * * *$ & $0.329 * * *$ & $1.283 * * *$ & $0.665 * * *$ & $0.591 * * *$ & $0.467 * * *$ & $0.824 * * *$ & $0.358 * * *$ & $1.151 * *$ & $0.785 * * *$ \\
\hline Other Infraction & 0.988 & 1.048 & $2.168 * * *$ & $1.287 * * *$ & $0.856^{* *}$ & $0.709 * * *$ & $0.804 * * *$ & 0.901 & $2.147 * * *$ & $0.870 * *$ & $0.791 * * *$ & $0.918 * * *$ \\
\hline Truancy & $0.363 * * *$ & $0.206^{* * *}$ & $0.123 * * *$ & $0.0697 * * *$ & $0.408 * * *$ & $0.306 * * *$ & $0.297 * * *$ & $0.183 * * *$ & $0.150 * * *$ & $0.0781 * * *$ & $0.368 * * *$ & $0.322 * * *$ \\
\hline Bullying & $1.145 * * *$ & 1.498 & $0.555 * * *$ & $0.327 * * *$ & $0.520 * * *$ & $0.439 * * *$ & 1.026 & 1.330 & $0.486 * * *$ & $0.405 * * *$ & $0.453 * * *$ & $0.545 * * *$ \\
\hline Tobacco & $1.620 * * *$ & 0.984 & $0.515 * * *$ & $1.916 * * *$ & $0.162 * * *$ & $0.193 * * *$ & $1.698 * * *$ & 0.995 & $0.435 * * *$ & $1.944 * * *$ & $0.134 * * *$ & $0.230 * * *$ \\
\hline Assault & $3.479 * * *$ & $22.61 * * *$ & 0.998 & $7.094 * * *$ & $0.515 * * *$ & $0.332 * * *$ & $3.292 * * *$ & $21.15^{* * * *}$ & $0.861 * * *$ & $8.905 * * *$ & $0.429 * * *$ & $0.413 * * *$ \\
\hline Vandalism & $1.658 * * *$ & $5.013 * * *$ & $0.591 * * *$ & 0.862 & $0.669 *$ & $0.550 * * *$ & $1.515 * * *$ & $4.641 * * *$ & $0.520 * * *$ & 0.895 & $0.570 * *$ & $0.670 * * *$ \\
\hline Drugs and Alcohol & $19.63 * * *$ & $349.4 * * *$ & $0.0239 * * *$ & $15.17 * * *$ & $0.226 * *$ & $0.162 * * *$ & $21.57 * * *$ & $379.0 * * *$ & $0.0244 * * *$ & $20.89 * * *$ & $0.186 * *$ & $0.180 * * *$ \\
\hline Gangs and Fighting & $4.281 * * *$ & $5.045^{* * *}$ & $0.557 * * *$ & $0.586^{* * *}$ & $0.174 * * *$ & $0.248 * * *$ & $3.983 * * *$ & $4.728 * * *$ & $0.486 * * *$ & $0.683 * * *$ & $0.152 * * *$ & $0.296 * * *$ \\
\hline Weapon & $7.510 * * *$ & $195.4 * * *$ & $0.250 * * *$ & $21.01 * * *$ & $0.238^{*}$ & $0.281 * * *$ & $7.615 * * *$ & $193.6 * * *$ & $0.236 * * *$ & $26.79 * * *$ & $0.208 * *$ & $0.344 * * *$ \\
\hline Infraction Order & $\mathrm{Y}$ & $\mathrm{Y}$ & $\mathrm{Y}$ & $\mathrm{Y}$ & $\mathrm{Y}$ & $\mathrm{Y}$ & $\mathrm{Y}$ & $\mathrm{Y}$ & $\mathrm{Y}$ & $\mathrm{Y}$ & $\mathrm{Y}$ & $\mathrm{Y}$ \\
\hline \multicolumn{13}{|l|}{ District Charcteristics } \\
\hline $\ln ($ Enrollment $)$ & & & & & & & $1.168 * * *$ & 1.035 & $0.478 * * *$ & $3.377 * * *$ & $0.676 * * *$ & $1.884 * * *$ \\
\hline$\%$ Minority & & & & & & & $3.146 * * *$ & $1.587^{*}$ & $0.433 * * *$ & 1.410 & $2.017 * * *$ & $0.122 * * *$ \\
\hline$\%$ FRL-eligible & & & & & & & 1.081 & 0.730 & $1.850 * * *$ & $90.49 * * *$ & $0.133 * * *$ & $27.56 * * *$ \\
\hline$\% \mathrm{SpEd}$ & & & & & & & $0.0462 * * *$ & 0.228 & $0.103 * * *$ & $0 * * *$ & 1.835 & $420.6 * * *$ \\
\hline Region & & & & & & & $\mathrm{Y}$ & $\mathrm{Y}$ & Y & $\mathrm{Y}$ & $\mathrm{Y}$ & $\mathrm{Y}$ \\
\hline Constant & $0.358 * * *$ & $0.0005 * * *$ & $0.719 * * *$ & $0.0013 * * *$ & $0.0419 * * *$ & $0.644 * * *$ & $0.0642 * * *$ & $0.0003 * * *$ & $124.3 * * *$ & $0.0000 * * *$ & $2.908 * * *$ & $0.0006^{* * *}$ \\
\hline$N$ of cases & 651,804 & & & & & & 651,804 & & & & & \\
\hline Model X & 59,530 & & & & & & 80,337 & & & & & \\
\hline Pseudo $\mathrm{R}^{2}$ & 0.1082 & & & & & & 0.1867 & & & & & \\
\hline
\end{tabular}

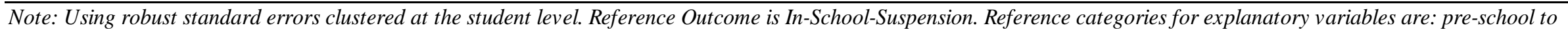
eighth grade, disorderly conduct, in northwest region, and first infraction. 
what "other" means to various school districts. However, in the next analysis that controls for districtlevel characteristics, we will be able to see differences in the use of each type of consequence for different types of districts.

In addition to disparities by race, we can see relative risk ratios for students in grades the ninth to twelfth grades, relative to students in pre-kindergarten through eighth grade. Students in secondary school (9 to 12), relative to elementary school (pre-K to 8) are slight more likely to receive OSS, more likely to receive expulsion or ALE, and less likely to receive corporal punishment, no action, or “other.” These differences by grade level appear consistent with our expectations, because exclusionary practices such as ISS and OSS make up a larger proportion of all consequences at the secondary level (about 73\%) than at the elementary level (about 62\%). In addition, corporal punishment makes up a larger proportion of all consequences at the elementary level (19\%) than at the secondary level (7\%). See Table 4.

Table 4: Elementary and Secondary Frequency of Consequences, Arkansas (2010-11 to 2012-13)

\begin{tabular}{|c|c|c|c|c|c|c|c|c|}
\hline & $\begin{array}{c}\text { In School } \\
\text { Suspension }\end{array}$ & $\begin{array}{c}\text { Out-of- } \\
\text { School } \\
\text { Suspension }\end{array}$ & Expulsion & $\begin{array}{c}\text { Corporal } \\
\text { Punishment }\end{array}$ & ALE & No Action & $\begin{array}{l}\text { Other } \\
\text { Action }\end{array}$ & Total \\
\hline Grades P-8 & 138,885 & 98,484 & 702 & 73,201 & 1,451 & 3,616 & 64,362 & 380,701 \\
\hline$\%$ of P-8 Total & $36 \%$ & $26 \%$ & $0 \%$ & $19 \%$ & $0 \%$ & $1 \%$ & $17 \%$ & $100 \%$ \\
\hline Grades 9 - 12 & 122,874 & 76,528 & 1,144 & 20,021 & 1,570 & 1,543 & 47,423 & 271,103 \\
\hline$\%$ of 9-12 Total & $45 \%$ & $28 \%$ & $0 \%$ & $7 \%$ & $1 \%$ & $1 \%$ & $17 \%$ & $100 \%$ \\
\hline All Grades & 261,759 & 175,012 & 1,846 & 93,222 & 3,021 & 5,159 & 111,785 & 651,804 \\
\hline
\end{tabular}

The results in Model 1 of Table 3 also display the likelihood of receiving different types of consequences for different infractions, relative to disorderly conduct. These relative risk ratios also communicate the importance of controlling for infraction committed. For example, certain infractions such as drugs/alcohol or weapons are much more likely than disorderly conduct to result in expulsions, referrals to ALE, or OSS. 
Controls for infraction order (essentially repeat offenses by a student in the same school in the same year) were included, and as expected, punishments tended to be more severe when associated with repeat offenses. All else equal, the likelihood of receiving OSS, Expulsion, ALE, and "other" action, relative to ISS, is higher for repeat offenses than for the first infraction. This supports the idea that OSS, expulsions, ALE, and perhaps “other" actions, on average, are considered more severe consequences than ISS, and therefore more likely to occur when a student has multiple repeat offenses. On the other hand, all else equal, the likelihood of receiving corporal punishment or no action is lower for repeat offenses than for the first infraction.

The results from Model 1 confirm two ideas: 1) there is valuable information related to the infraction type and frequency that should be included in discipline policy research and 2) even after controlling for these important factors, there are still disproportionalities by race. It's important to realize, however, that these disparities are found in models which do not include school fixed effects. Therefore, it is certainly possible that some of these disproportionalities could be attributed to minority students attending schools with different discipline policies. As one example of differences in disciplinary practices by region, consider the use of corporal punishment. Table 5 indicates that about a quarter of all consequences in the Southeast and Northeast regions (the Mississippi Delta) are corporal punishment. Corporal punishment is used much less frequently in the Northwest corner of the state (8 percent of cases). In the next research question, therefore, we control for certain district level characteristics and region.

Table 5: Corporal Punishment by Region (2010-11 to 2012-13)

\begin{tabular}{lrrrrrr}
\hline & Southeast & Northeast & Southwest & Central & Northwest & AR Total \\
\hline \# of Instances & 14,341 & 31,427 & 14,494 & 17,109 & 15,851 & 93,222 \\
$\%$ of All Consequences & $26 \%$ & $25 \%$ & $17 \%$ & $9 \%$ & $8 \%$ & $14 \%$ \\
\hline
\end{tabular}


Research Question 2: After additionally controlling for district level characteristics (size, demographics, and region), does a student's race still predict the type of consequence received?

In Model 2 of Table 6, additional control variables include district level characteristics (natural $\log$ of enrollment, percent minority students, percent FRL-eligible, and percent special education students) as well as region. These additional covariates control for some of the local culture and policies that may be associated with certain types of districts and regions.

The results in Model 2 indicate that all else equal, black students are still more likely to receive OSS, expulsion, and ALE, although the relative risks associated with each of these, relative to ISS, has decreased. Notably, the relative risk ratio of OSS relative to ISS for black students, relative to white students, is only 1.09, and therefore relatively close to one. Also, the relative odds of receiving ALE (instead of ISS), for black students, decreased from 6.6 times as likely in Model 1 to 1.4 times as likely in Model 2. Interestingly, in Model 2, the difference in the odds of receiving corporal punishment or no action relative to ISS are no longer significant.

To understand why some of these racial disproportionalities decrease in Model 2, we should also study the relationship between district characteristics/region and consequence type received. Students in larger districts, on average, are more likely to receive OSS, ALE, or "other" action, relative to ISS. This could be driven by a few special district cases, however. For example, one of the top five largest school districts serves about $4 \%$ of the state enrollment, but represented $12 \%$ of the "other" action cases. Students in larger districts, on the other hand, are less likely to receive corporal punishment or no action, relative to ISS.

In addition, students in districts serving a greater proportion of minority students are more likely to receive OSS, expulsion, or no action, relative to ISS, although the relative risk-ratio for expulsion is only marginally significant. While we may expect this effect for severe exclusionary consequences such as OSS and expulsion, the increased odds of no action is somewhat counter- 
intuitive if we are to believe that districts with more minority students are likely to use harsher consequences. Students in districts serving a greater proportion of minority students are less likely to receive corporal punishment or an "other (non-specified)" consequence, relative to ISS.

Students in districts serving more low-income students (as measured by FRL-eligibility) are almost twice as likely to receive corporal punishment, relative to ISS, over 27 times as likely to receive “other" action relative to ISS, and over 90 times as likely to receive referrals to ALE, relative to ISS. These large differences by district demographics indicate some potentially worrisome discipline policies in districts serving high proportions of low income students.

The differences by region were hidden in the table, but students in the southern regions of the state are less likely to receive no action, relative to ISS. In addition, students in the Mississippi Delta (Northeast and Southeast) or the Central part of the state are more likely to receive corporal punishment, relative to ISS.

Research Question 3: Among the socio-economic and demographic indicators that should not be related to disciplinary outcomes, if discipline is administered fairly and consistently, which is the largest driver of the disparities in disciplinary outcomes?

In Model 3 of Table 6, additional controls for student-level demographics were included. While we are not suggesting that any of these demographics are valid determinants of differential discipline outcomes, it is important to see whether the disproportionalities due to race still hold up, or whether other student-level demographics appear to be driving the disparities. In Model 3, there are disparities by gender that are in all cases larger than the disparities by race for OSS, expulsion, corporal punishment, and referrals to ALE, relative to ISS. Males are also less likely to receive no action or an “other (non-specified) action" than females. 
Table 6: Multinomial Regression of Consequence, AR K-12 ('10-11 to '12-13); Relative-Risk Ratio MODEL 3

\begin{tabular}{|c|c|c|c|c|c|c|}
\hline Group & $\begin{array}{c}\text { Out-of-School } \\
\text { Suspension }\end{array}$ & Expulsion & $\begin{array}{c}\text { Corporal } \\
\text { Punishment }\end{array}$ & ALE & No Action & Other Action \\
\hline \multicolumn{7}{|l|}{ Race/Ethnicity } \\
\hline Black & $1.069 * * *$ & $1.422 * * *$ & 1.048 & $1.269 * * *$ & 0.977 & $0.799 * * *$ \\
\hline Hispanic & $0.787 * * *$ & 0.971 & $0.760 * * *$ & $0.604^{*}$ & $0.676^{* * *}$ & $1.294 * * *$ \\
\hline Asian & 0.949 & $0.389^{*}$ & 0.784 & $0.302 * *$ & $0.428 * *$ & $1.212 * * *$ \\
\hline Native American & $0.867 * *$ & 0.812 & $0.784^{*}$ & $0.097 * *$ & $0.571 * *$ & $1.205 * * *$ \\
\hline Two or More Races & $0.842 * * *$ & 0.726 & 1.007 & 0.740 & 1.066 & $1.101 * *$ \\
\hline Grade 9-12 & $1.137 * * *$ & $2.042 * * *$ & $0.367 * * *$ & $1.504 * * *$ & $0.540 * * *$ & $0.779 * * *$ \\
\hline Male & $1.141 * * *$ & $1.735^{* * *}$ & $1.843 * * *$ & $1.396 * * *$ & $0.862 * * *$ & $0.888 * * *$ \\
\hline FRL & $1.161 * * *$ & $1.211 * * *$ & $1.198 * * *$ & $1.461 * * *$ & $1.213 * * *$ & $0.869 * * *$ \\
\hline Special Education & $1.114 * * *$ & $0.560 * * *$ & 1.009 & 1.011 & 0.977 & $0.925 * * *$ \\
\hline Limited English Proficient & $0.884 * * *$ & 0.933 & $0.676 * * *$ & 0.784 & $0.310 * * *$ & $0.899 * * *$ \\
\hline \multicolumn{7}{|l|}{ Infraction Type } \\
\hline Insubordination & $0.593 * * *$ & $0.467 * * *$ & $0.840 * * *$ & $0.358 * * *$ & $1.145^{* *}$ & $0.787 * * *$ \\
\hline Other Infraction & $0.814 * * *$ & 0.909 & $2.220 * * *$ & $0.876^{* *}$ & $0.790 * * *$ & $0.911 * * *$ \\
\hline Truancy & $0.302 * * *$ & $0.188 * * *$ & $0.161 * * *$ & $0.080 * * *$ & $0.364 * * *$ & $0.318 * * *$ \\
\hline Bullying & 1.029 & 1.332 & $0.489 * * *$ & $0.404 * * *$ & $0.456 * * *$ & $0.545 * * *$ \\
\hline Tobacco & $1.664 * * *$ & 0.941 & $0.410 * * *$ & $1.847 * * *$ & $0.136 * * *$ & $0.233 * * *$ \\
\hline Assault & $3.265 * * *$ & $21.34 * * *$ & $0.856 * * *$ & $8.747 * * *$ & $0.431 * * *$ & $0.416 * * *$ \\
\hline Vandalism & $1.508 * * *$ & $4.520 * * *$ & $0.521 * * *$ & 0.875 & $0.578 * *$ & $0.679 * * *$ \\
\hline Drugs and Alcohol & $21.94 * * *$ & $367.5 * * *$ & $0.0254 * * *$ & $20.78 * * *$ & $0.184 * *$ & $0.177 * * *$ \\
\hline Gangs and Fighting & $3.994 * * *$ & $4.782 * * *$ & $0.483 * * *$ & $0.688 * * *$ & $0.153 * * *$ & $0.296 * * *$ \\
\hline Weapon & $7.515 * * *$ & $181.1 * * *$ & $0.224 * * *$ & $25.69 * * *$ & $0.211 * *$ & $0.347 * * *$ \\
\hline Infraction Order & $\mathrm{Y}$ & $\mathrm{Y}$ & $\mathrm{Y}$ & Y & $\mathrm{Y}$ & Y \\
\hline \multicolumn{7}{|l|}{ District Characteristics } \\
\hline $\ln ($ Enrollment $)$ & $1.171 * * *$ & 1.044 & $0.476 * * *$ & $3.350 * * *$ & $0.679 * * *$ & $1.880 * * *$ \\
\hline$\%$ Minority & $3.250 * * *$ & $1.611^{*}$ & $0.467 * * *$ & 1.500 & $2.092 * * *$ & $0.119 * * *$ \\
\hline$\%$ FRL-eligible & 1.027 & 0.675 & $1.749 * * *$ & $71.92 * * *$ & $0.119 * * *$ & $28.60 * * *$ \\
\hline$\% \mathrm{SpEd}$ & $0.040 * * *$ & 0.415 & $0.0908 * * *$ & $0.000 * * *$ & 1.862 & $475.8 * * *$ \\
\hline Region & $\mathrm{Y}$ & Y & Y & Y & Y & Y \\
\hline Constant & $0.0523 * * *$ & $0.0002 * * *$ & $70.78 * * *$ & $0.0000 * * *$ & $2.923 * * *$ & $0.0007 * * *$ \\
\hline$N$ of cases & 651,804 & & & & & \\
\hline Model $X^{2}$ & 81,312 & & & & & \\
\hline Pseudo $\mathrm{R}^{2}$ & 0.1903 & & & & & \\
\hline
\end{tabular}

Note: Using robust standard errors clustered at the student level. Reference Outcome is In-SchoolSuspension. Reference categories for explanatory variables are: pre-school to eighth grade, disorderly conduct, in northwest region, and first infraction. 
The disparities by FRL-status are often similar in magnitude to the racial disparities. In several cases the relative-risk ratio related to the disparities for FRL students are larger than the relative-risk ratios related to the disparities for black students (OSS, corporal punishment, ALE, and no action), but for expulsion, at least, it appears that the disparities are driven more by race than by FRL-status.

Last, we can see that OSS is relatively more likely than ISS for special education students relative to non-special education students. One interpretation could be that schools do not feel adequately prepared to support special education students within the typical ISS environment.

Model 3 presents a variety of student-level demographics associated with disproportional use of disciplinary consequences, but even after controlling for these additional factors, there are still significant disparities by race. Table 7 shows the key relative risk-ratios for race in each model. The disparities for black and Hispanic students are surprisingly similar in Models 2 and 3. In some cases (particularly for Hispanics), the disparities actually increased. The only relative risk ratio for either black or Hispanic students that lost significance between Model 2 and Model 3 was that of receiving ALE, relative to ISS, for Hispanic students. This effect is now only marginally significant.

Table 7: Relative-Risk Ratios on Race from Multinomial Regression of Type of Consequence, Arkansas Panel A: Relative-Risk-Ratio for Black Students Relative to White Students

\begin{tabular}{ccccccc}
\hline \multicolumn{1}{c}{$\begin{array}{c}\text { Out-of- } \\
\text { School } \\
\text { Suspension Expulsion Punishment }\end{array}$} & ALE & No Action & Other Action \\
\hline Model 1 & $2.089^{* * *}$ & $1.983^{* * *}$ & $0.648^{* * *}$ & $6.577^{* * *}$ & $0.769^{* * *}$ & $0.626 * * *$ \\
Model 2 & $1.090^{* * *}$ & $1.445^{* * *}$ & 1.043 & $1.358^{* * *}$ & 1.026 & $0.785^{* * *}$ \\
Model 3 & $1.069 * * *$ & $1.422^{* * *}$ & 1.048 & $1.269 * * *$ & 0.977 & $0.799 * * *$ \\
\hline
\end{tabular}

Panel B: Relative-Risk-Ratio for Hispanic Students Relative to White Students

Out-of-

\section{School Corporal}

Suspension Expulsion Punishment ALE No Action Other Action

\begin{tabular}{lcccccc}
\hline Model 1 & $0.854 * * *$ & 0.881 & $0.306 * * *$ & 1.211 & $0.315^{* * *}$ & $1.844^{* * *}$ \\
Model 2 & $0.752^{* * *}$ & 0.994 & $0.660^{* * *}$ & $0.577 * * *$ & $0.433 * * *$ & $1.192^{* * *}$ \\
Model 3 & $0.787 * * *$ & 0.971 & $0.760^{* * *}$ & $0.604 *$ & $0.676^{* * *}$ & $1.294 * * *$ \\
\hline
\end{tabular}




\section{CONCLUSION AND POLICY IMPLICATIONS}

\section{Policy Implications}

The results of the multinomial logit analysis reveal that even after controlling for a variety of infraction information and district-level characteristics, certain student demographic indicators are associated with the type of consequence received. Black students, males, and low-income students (eligible for free- and reduced- lunch) were more likely to receive certain types of exclusionary consequences such as out-of-school suspension, expulsion, and referrals to Alternative Learning Environments relative to in-school-suspension. For example the relative risk of expulsion for black students is about 1.4 times the risk of ISS, even after controlling for infraction-level details, other student characteristics, the region, and district-level characteristics, indicating that black students receive expulsions for frequently than white students in the state. The relative risk of expulsion for male students is about 1.7 times the risk of ISS, and the relative risk of corporal punishment for male students is about 1.8 times the risk of ISS, indicating that male students have an increased risk of expulsion relative to females.

State policy makers should be concerned with both the different treatment of students based on demographic factors as well as the disparate impact of policies for different groups of students. Clearly, there are large differences in outcomes in Model 1, which doesn't account for district level characteristics or region, but there are still large disproportionalities by race, gender, and other student indicators after controlling for these factors.

Another important issue for state policy makers to consider is the current reporting of referral data through district self-reports. Arkansas and other states should make clear and consistent rules for how referrals are to be reported by all school districts. In addition, more work should be done to explain these disparities as well as their relationship to student achievement. 


\section{Further Research}

Future analyses will focus on the relationship between student discipline history and special education identification, as well as the relationship between student achievement and discipline. In addition, in order to provide practical data for state or local policymakers to utilize, we plan to conduct a residual analysis to identify the types of schools that tend to dole out more severe or longer consequences overall, and for certain subgroups of students in particular. Similar to a value added model for punishments, each infraction's residual (the number of days above or below average) will represent "strictness" which can then be analyzed at different subgroup and school levels. 


\section{REFERENCES}

Anderson, K.P., Ritter, G.W., \& Boyd, A. (Forthcoming). Do School Discipline Policies Treat Students Fairly? A Second Look at School Discipline Rate Disparities.

Arkansas Advocates for Children and Families. (2013). Keeping Kids in Class: Fixing Racial Disparities in School Discipline. Retrieved from: http://www.aradvocates.org/publications/keeping-kids-in-class-fixing-racial-disparities-inschool-discipline/

Arkansas Department of Education. Discipline Policies/Student Handbooks. Retrieved from: http://www.arkansased.org/divisions/public-school-accountability/equity-assistance/disciplinepolicies-student-handbooks

Children's Defense Fund. (1975). School Suspensions: Are they Helping Children? Washington Research Project, Cambridge, MA. Retrieved from: http://files.eric.ed.gov/fulltext/ED113797.pdf

Losen, D., \& Gillespie, J. (2012). Opportunities Suspended: The Disparate Impact of Disciplinary Exclusion from School. Civil Rights Project, UCLA. Retrieved from: http://civilrightsproject.ucla.edu/resources/projects/center-for-civil-rights-remedies/school-toprison-folder/federal-reports/upcoming-ccrr-research/losen-gillespie-opportunity-suspended2012.pdf

Skiba., R. J., Chung, C.G., Trachok, M., Baker, T. L., Sheya, A., \& Hughes, R. L. (2014). Parsing Disciplinary Disproportionality: Contributions of Infraction, Student, and School Characteristics to Out-of-School Suspension and Expulsion. American Educational Research Journal, 51(4): 640-670. 
Skiba, R. J., Horner, R., Chung, C. G., Rausch, M. K., May, S., \& Tobin, T. (2011). Race is Not Neutral: A National Investigation of Black and Latino Disproportionality in School Discipline. School Psychology Review, 40(1): 85-107.

Skiba, R. J., Michael, R., Nardo, A., \& Peterson, R. (2002). The Color of Discipline: Source of Racial and Gender Disproportionality in School Punishment. The Urban Review, 34(4), 317-342.

Sullivan, A. L., Klingbeil, D. A., \& Van Norman, E. R. (2013). Beyond Behavior: Multilevel Analysis of the Influence of Sociodemographics and School Characteristics on Students' Risk of Suspension. Children, Research, and Public Policy, 42(1), 99-144.

US Department of Education and US Department of Justice. (2014). Dear Colleague Letter on the Nondiscriminatory Administration of School Discipline. Retrieved from: http://www2.ed.gov/about/offices/list/ocr/letters/colleague-201401-title-vi.html 


\section{Appendix A:}

Table A1: Three year average Arkansas K-12 enrollment and discipline data (2010-11 to 2012-13)

\begin{tabular}{lrr}
\hline & $\begin{array}{c}\text { Total Arkansas } \\
\text { Enrollment }\end{array}$ & $\begin{array}{r}\text { Total Discipline } \\
\text { Data }\end{array}$ \\
\hline Unit of Analysis & Student & Incident \\
\% Male & $51.2 \%$ & $70.6 \%$ \\
\% Female & $48.8 \%$ & $29.4 \%$ \\
\% White & & \\
\% Black & $64.2 \%$ & $43.4 \%$ \\
\% Hispanic & $21.0 \%$ & $43.6 \%$ \\
\% Asian & $10.4 \%$ & $9.2 \%$ \\
\% Native American & $2.0 \%$ & $0.8 \%$ \\
\% Two or More Races & $0.7 \%$ & $0.9 \%$ \\
& $1.7 \%$ & $2.2 \%$ \\
\% FRL-eligible & & \\
\% Special Education & $60.6 \%$ & $71.0 \%$ \\
\% LEP & $11.0 \%$ & $18.0 \%$ \\
& $7.0 \%$ & $6.0 \%$ \\
Grade K-5 & & \\
Grade 6-8 & $47.3 \%$ & $23.0 \%$ \\
Grade 9-12 & $23.4 \%$ & $35.4 \%$ \\
Preschool/Ungraded & $29.2 \%$ & $41.6 \%$ \\
Observations & $0.1 \%$ & $0.1 \%$ \\
\hline
\end{tabular}

